Point of view

\title{
Temporal variation of rocky intertidal resident fish assemblages - patterns and possible mechanisms with a note on sampling protocols
}

\author{
Vítor C. Almada \& Cláudia Faria \\ Unidade de Investigação em Eco-Etologia, Instituto Superior de Psicologia Aplicada, R. Jardim do Tabaco \\ 34, P-1149-041 Lisboa, Portugal (Phone: 351-218811726; Fax: 351-218860954; E-mail: valmada@ispa.pt)
}

Accepted 22 October 2004

\section{Contents}

Abstract page 239

Introduction

Temporal variation in rocky intertidal fish assemblages

Seasonal versus inter-annual fluctuations

Factors that may control rocky intertidal fish populations

A methodological issue: the problem of destructive sampling

Key words: fish communities; resilience; rocky intertidal fish; stability; temporal variation

\begin{abstract}
In this paper we review the temporal patterns of variation of rocky intertidal resident fish assemblages and discuss possible mechanisms that may explain these patterns. These assemblages tend to be highly resilient and stable on an inter-annual basis, but tend to undergo marked seasonal fluctuations, as different species recruit and reach different phases of their life cycles. Larval supply is usually not a limiting factor suggesting that post-recruitment deterministic mechanisms exert a strong influence on assemblage organization. At methodological level, it is argued that traditional destructive sampling techniques should be avoided whenever possible. It is proposed that a deeper understanding of these assemblages requires more detailed information on intraspecific interactions between members of each constituent species, and information on the interactions between limited numbers of species for which mutually influences are particularly strong. It is argued that size, topography and biotic cover of a pool may provide a limited number of favourable sites for fishes of a given species and class size so that intraspecific competition, and possibly predation of the individuals less able to get access to best sites, may explain to a considerable extent the inter-annual stability and resilience of these assemblages.
\end{abstract}

\section{Introduction}

There has been a considerable number of studies on the dynamics of rocky intertidal fish assemblages (Table 1). Most of them stress the stability and resilience of these assemblages despite the fact that they deal with distinct faunas in many different parts of the world. For a recent review see Gibson and Yoshiyama (1999), who provided a fundamental work of reference on these topics. These findings are in sharp contrast with the marked fluctuations that often characterize the 
marine pelagic fish assemblages where inter-annual fluctuations in recruitment may affect the populations for several years, with notable consequences to the fisheries (e.g. Houde, 1987; Fogarty et al., 1991).

The stability and resilience of rocky intertidal fish assemblages are also remarkable when compared with the dynamics of coral reef fishes, where stochastic processes are frequently important and may cause substantial variation on the assemblage composition, at least at a local scale (e.g. Sale, 1975, 1977, 1978, 1979, 1980; Doherty, 1983). They are also in sharp contrast with studies of rocky intertidal invertebrates and algae, where at least a moderate level of disturbance seems to play an important role in maintaining assemblage diversity (e.g. Dayton, 1971, 1973, 1975; Harger and Landenberger, 1971; Connell, 1972; Sousa, 1979). The stability and resilience of their fish counterparts has often been viewed as providing evidence in support of the prevalence of deterministic processes in assemblage control as opposed to the fluctuations expected if the dynamics of the assemblage was dominated by stochastic processes (e.g. Thomson and Lehner, 1976; Grossman, 1982).

Deterministic control has traditionally been associated with stable and predictable environments, where biotic interactions play a leading role in community organization (e.g. Itzkowitz, 1977; Brock et al., 1979; Behrents, 1987; Larson, 1980a, b, c; Jones, 1987a, b; Dufour and Galzin, 1992; Mayr and Berger, 1992). The rocky intertidal habitat is a harsh and strongly fluctuating environment, subjected to frequent disturbances (e.g. Thomson and Lehner, 1976; Sousa, 1979), which makes understanding the role of stability and resilience a challenging task.

In this review we survey the literature on the temporal variation of rocky intertidal fish assemblages, with special emphasis on resident fish: those that after recruitment live and breed in the intertidal zone. The different methodological approaches used to study the dynamics of these assemblages are also reviewed and we discuss the advantages and limitations of the different research strategies. Finally, the possible mechanisms involved in the organization of rocky intertidal fish assemblages are discussed and we suggest approaches that may help to test different hypotheses concerning the mechanisms that control the dynamics of these assemblages.

We argue that it is not sufficient to study the assemblage as a whole, measuring abundance, biomass or diversity. We emphasize the need to study population dynamics of individual species, the mechanisms that control their numbers, the patterns of post-settlement mortality and behavioural interactions with conspecifics and other species. We also stress the need to test experimentally the importance of interspecific interactions. This bottom up approach may be a complement to the traditional assemblage oriented studies and contribute to a better understanding of assemblage dynamics as an integration of the dynamics of each constituent element.

\section{Temporal variation in rocky intertidal fish assemblages}

\section{General patterns}

The methods employed in studies of temporal patterns of variation in rocky intertidal fish assemblages (Table 1), involve mainly defaunation of pools at intervals that may vary from weeks to years, followed by community composition comparisons. Data analysis either involve correlational measures between ranks of constituent species in the different samples, or comparison of values of abundance, biomass or diversity in different times, or both. Some exceptions will be mentioned below.

The results of the surveyed studies can be summarized as follows:

(1) In most cases, faunal composition of the pools reassumed its pre-experimental structure in periods that ranged from a few weeks to a few months. This is true both for studies based on correlations or concordance indices and studies that compared species richness, diversity, equitability or biomass (e.g. Thomson and Lehner, 1976; Grossman, 1982, 1986; Beckley, 1985; Collette, 1986; Mistry et al., 1989; Mahon and Mahon, 1994; Willis and Roberts, 1996; Polivka and Chotkowski, 1998; Faria and Almada, 1999, 2001a; Silbershneider and Booth, 2001; Griffiths, 2003). 


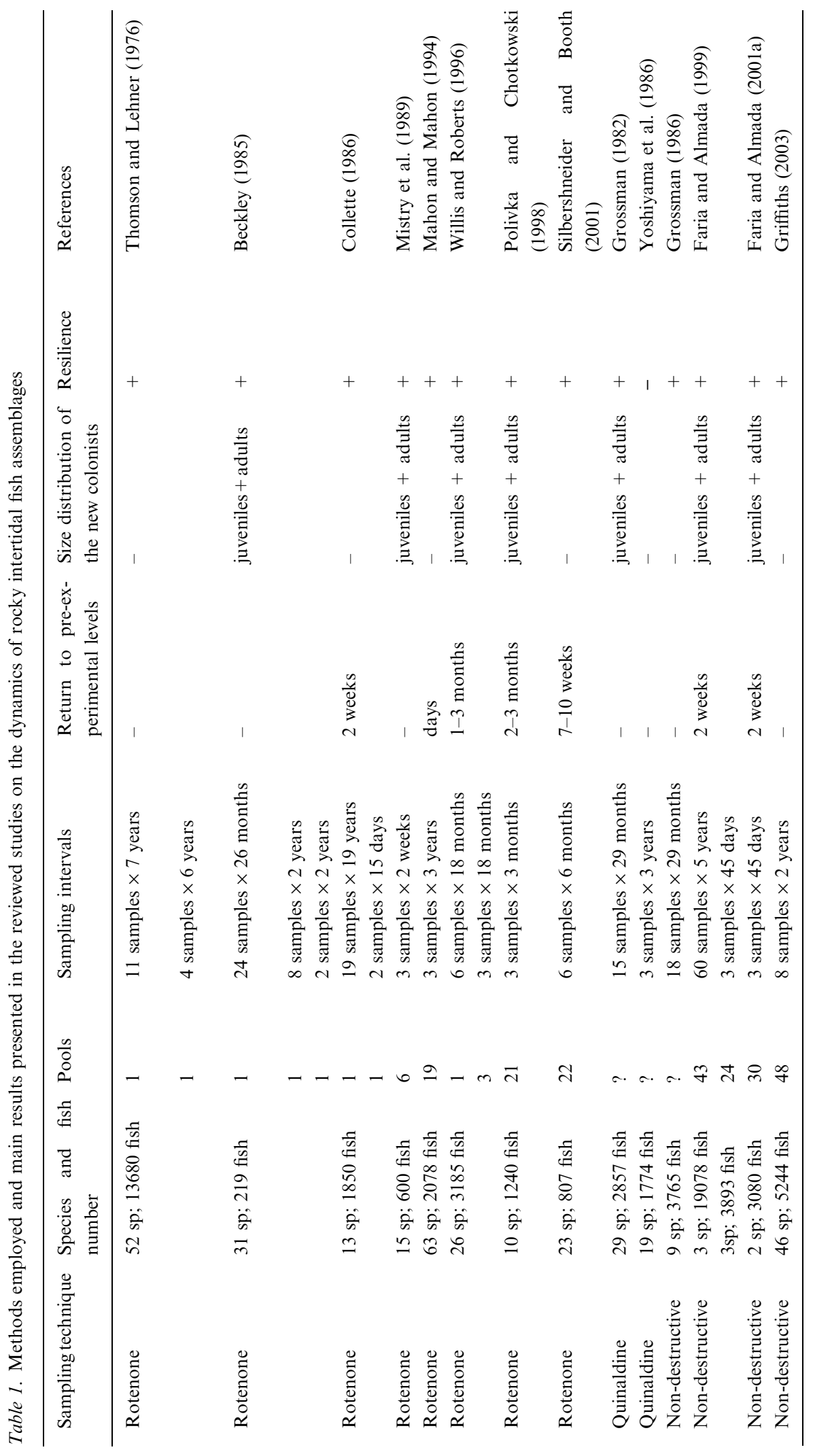


(2) In the few studies that surveyed the pools in the first tidal cycle after defaunation it was found that recolonisation had already started (e.g. Mistry et al., 1989; Mahon and Mahon, 1994).

(3) Analyses of size distribution of fishes before and after defaunation clearly indicate in several studies that recolonisation was not limited to the recruitment of settling juveniles from the plankton, but was also caused by larger juveniles or even adults that moved into the pools (e.g. Grossman, 1982; Beckley, 1985; Mistry et al., 1989; Willis and Roberts, 1996; Polivka and Chotkowski, 1998; Faria and Almada, 1999, 2001a).

(4) Studies conducted with time intervals of 1 year or more indicated that, in several cases, the sampled pools maintained a similar ichtyofaunal composition despite the long time periods between samples (e.g. Grossman, 1982, 1986; Collette, 1986; Mahon and Mahon, 1994; Faria and Almada, 1999).

These results argue strongly in favour of the stability, long-term persistence and resilience of rocky intertidal fish communities, as previously suggested by several authors (for a review see Gibson and Yoshiyama, 1999). However, some exceptions in special cases are worth mentioning:

\section{Natural disturbance}

Some studies describe natural disturbances apparently caused by episodes of environmental change. Thomson and Lehner (1976) stated that in the Northern Gulf of California (Mexico), low temperature extremes caused substantial mortality of fishes of tropical affinity, which temporarily altered assemblage composition. GodínezDomínguez et al. (2000) noted that after an El Niño/La Niña event the coastal fish fauna was also temporarily altered but returned to the pre-disturbance pattern in the next year. In a study of rocky intertidal fish, Davies (2000) reached a similar conclusion, with the return to pre-disturbance levels being attained soon after the end of the El Niño event.

Gibson (1967a) although in a very different context, noted that in the cold temperate waters of Britain, in some exceptionally cold winter periods, several individuals of Lipophrys pholis (a typical rocky intertidal resident species in west Europe) were found torpid or dying in the pools.
On these occasions of extreme cold some $L$. pholis left the pools and moved to the subtidal as evidenced by the prey items they consumed. This suggests that rock-pool fishes are subjected to episodic disturbances caused by environmental changes but, if conditions return to pre-disturbance levels, the assemblages are, at least in some cases, able to recover their pre-disturbance pattern.

Gibson and Yoshiyama (1999) called attention to the likelihood of high assemblage variability in areas that are near biogeographic boundaries. This association must be taken into consideration when comparing similar studies conducted in different parts of the world. Even when a study site is not in close proximity to a major biogeographic boundary, it is important to note that different species often differ in their distributional ranges, presumably due to differences in their tolerance to environmental factors. Yoshiyama et al. (1986) provided evidence for this effect showing how individual members of rocky intertidal fish assemblages along the North America Pacific coast, gradually changed in relative abundance when one moves from south to north. This suggests that in locations significantly distant from biogeographic boundaries, some of the species may be near their southern or northern distribution limit, being more vulnerable to change with climatic fluctuations. This source of temporal variation has also been noted for fish in other marine habitats such as subtidal reefs and soft bottoms (Stephens et al., 1984; Rogers and Millner, 1996).

Both the El Niño Southern Oscilation (ENSO) in the Pacific and the North Atlantic Oscilation (NAO) in the Atlantic, illustrate the fact that there are many changes in sea temperature and other oceanographic parameters that undergo cyclic variations at a variety of scales. Thus, it is likely that, for many rocky intertidal fish species that are near their distributional limits, cyclic fluctuations in abundance are frequent. At the assemblage level, this means that we must expect cycles of variation in abundance of various durations for a fraction of each assemblage constituents. Traditional comparisons based on indices of species richness, diversity, total biomass or number of fish are not appropriate to detect variation involving a single species or a limited group of assemblage elements. When the number of species is high, 
correlations between ranks may also fail to detect changes of individual species if they do not affect the overall pattern, or if the changes are not sufficient to markedly modify the rank of the affected species.

\section{Uncommon species}

Most studies summarized in Table 1 emphasize that less common species, which often are represented by one or a few individuals in a pool, may often fail to return after defaunation and thus their numbers do not conform to the stability and resilience pattern shown by abundant species. If we view each pool as a random sample of an assemblage that inhabits a wide area, and assuming that the species do not differ in their colonizing ability, we could expect abundant species to occur in pools in proportions that approximate their relative abundance in the wider habitat patch. Uncommon species, on the other hand may be too few to provide a representative sample across all habitats. Thus, the absence of recolonisation of rare species in a pool does not provide conclusive evidence in favour or against the stability and resilience of its populations when few pools are sampled. This situation emphasizes the problem of sampling across spatial scales. Many studies in our review were based on a small number of pools (2-23), with the most comprehensive including up to 48 pools (see Table 1). A number of pools sufficient to accurately sample common species may be totally inappropriate to study the variation of rare ones.

In principle the more uncommon a species is, the larger the number of pools that are required to sample it adequately. However, even this simple reasoning assumes that the pools are sufficiently similar to each other so that each one represents a portion of the same habitat, and that there are no associations between rarity of a species and its relative degrees of mobility and gregariousness. Thus, heterogeneity among pools, rare species that are exceptionally mobile or sedentary, or those that display behaviours that make them atypically aggregated or spaced, may complicate the design of schemes to sample them accurately.

\section{Selection of time intervals and spatial scales of sampling}

Some studies state that repeated defaunation in intensively sampled sites seems to cause a decrease in recolonisation, probably because the sources of fish surrounding the pool are gradually depleted (Yoshiyama et al., 1986). This problem again emphasizes the need for careful consideration of scales, both in space and time. Only in one study (Yoshiyama et al., 1986) could we find information on the size of the rocky intertidal habitat where sample pools were located, and the proportion of the total habitat corresponding to the defaunated pools. If a pool is defaunated it may be recolonised either by new juveniles, that settle from the plankton, or by larger fish that move from surrounding areas. Although there are studies that demonstrate both processes (e.g. Beckley, 1985; Grossman, 1986; Mistry et al., 1989; Mahon and Mahon, 1994; Polivka and Chotkowski, 1998), we could not find information sufficiently detailed to access their relative importance. For several resident species of rock intertidal fish, there is evidence suggesting that they hardly venture into the subtidal and avoid crossing areas devoid of hard substratum, like sandy beaches. The actual rates at which each species is able to cross these barriers is however unknown.

In this respect, defaunation experiments of pools located in isolated rock outcrops may be especially informative. Comparison of such results with those for pools located in larger habitat patches, where other pools exist and fish can move easily, can provide useful information to access the relative importance of settlement versus the migration of larger juveniles and adults. In a similar vein, comparisons of the inter-annual variation of numbers of fish in pools situated in small rock outcrops and those located in large platforms would help to assess the role of natural migration in the control of the assemblage of rocky intertidal resident fish. Indeed, many of these species hardly venture into the subtidal, so isolated pools may effectively prevent movements of settled fish from or to other pools.

The problem of sampling scale times has also been underestimated. While some studies claim resilience based on short term experiments, where both recruitment and migration of larger fish may occur, others refer to sampling episodes separated by such long time intervals that different recruitment processes must have occurred, and in some cases, for short-lived species, all the individuals must have been replaced. Obviously, the results of recolonization after a few weeks and similarities of 
numbers taken several years apart probably depend on different underlying mechanisms.

\section{Seasonal versus inter-annual fluctuations}

The studies we reviewed provide a spectrum of time scales that range from several weeks to several years. Conclusions about stability and resilience were, in some cases, derived from the return of numbers of fish to pre-disturbance levels based on samples taken in different years.

This general pattern is made more complex by marked variation in assemblage composition and total number of fish within any annual cycle. As different species recruit to the pools, large numbers of juveniles may be added to the assemblage, a process that for most species, has a strong seasonal component (e.g. Grossman, 1982; Beckley, 1985; Mahon and Mahon, 1994; Willis and Roberts, 1996; Griffiths, 2003). This effect of seasonality of recruitment is not restricted to temperate habitats and as been also documented in coral reefs (e.g. Letourner, 1996).

In addition to the effects of variable recruitment, some species may show ontogenetic shifts in habitat (e.g. Gibson, 1972; Faria and Almada, 2001a), which are also frequent in other fish assemblages, like those of coral reefs (e.g. Auster, 1988; Letourner, 1996). On the western coast of Portugal, for instance, juveniles of L. pholis, Coryphoblennius galerita and Gobius cobitis recruit to a wide variety of pools during the spring. Small juveniles appear in large numbers in very shallow pools, only a few centimeters deep. In the next few months, after the end of recruitment, these shallow pools become devoided of fish (Faria and Almada, 2001a). It is unclear if the growing juveniles die or move out of these pools. In deeper and topographically more complex pools, juveniles continue to be present after the end of recruitment, and the growth of the young-of-the-year can be followed during summer and autumn (Faria et al., 1996; Almada et al., 1996a). L. pholis and G. cobitis juveniles which reach about 6-7 cm by September/October, begin to leave these pools and colonize adult habitat in intertidal crevices in the case of L. pholis, or in deep channels (regularly connected with the sea), with boulders and sand, for G. cobitis. C. galerita, remains in the pools where the juveniles grew, but a large proportion of the adult males leave these pools periodically to occupy holes in rocks that will serve as nest sites during the breading season. These mates return to the pools after the end of reproduction (Faria and Almada, 2001a).

These examples illustrate the wide seasonal variation in numbers, size distribution and abundance of different species found in this assemblage related to recruitment and breeding. However, comparisons of numbers of species in the same pool during the same season in successive years, using non-destructive censusing (all the fish returning alive to their pool) revealed very high and significant inter-annual correlations (Faria and Almada, 1999). Thus, in different years at a given time of the year, each pool may bear an assemblage very similar to that of the previous year, although from season-to-season very strong assemblage changes of an almost cyclical kind can be observed.

This pattern is made even more remarkable when we consider that, apart from changes in the fish numbers caused by recruitment, mortality or breeding migrations, these pools are often subjected to very drastic biotic and physical seasonal changes. In the warm temperate waters of western Portugal, there are strong seasonal changes in algal cover, which after the spring and summer growing period are almost completely destroyed by winter storms. Each spring is also marked by the arrival of large numbers of non-resident fish such as juvenile Diplodus sargus or Atherina presbyter which, after being present in high numbers during the spring and summer, are virtually absent from the pools in the winter (unpublished data). In winter, even the physical composition of the habitat may change. After storms some pools are sometimes filled with sand and displacement of large boulders has been observed. It is unknown what the behaviour of the resident fish is during these stormy periods. Many of the changes are reverted in spring when the predominant wind and wave direction shift from southwest to northwest, and the habitat reassumes much of the same characteristics found in the previous spring.

Finally, although several studies, including our own, indicate that there may be important interannual differences in the intensity of recruitment among different species, the surveyed literature supports the following conclusions:

(1) Recruitment failures are apparently very rare (but see Yoshiyama et al., 1986) and we could 
not find examples where an insufficient larval supply was considered a major factor determining assemblage composition.

(2) When we compared the smallest and largest figures for recruitment in different years, the variation was relatively small, the highest figures being only three times larger than the smallest (Faria and Almada, 1999), a figure that is low when compared with variations reported for pelagic marine fishes.

(3) The inter-annual variation in recruitment is greater than the inter-annual variation in larger juveniles or adults. Years where numbers are relatively high may recruit two times more fish than in the worst years (Faria and Almada, 1999; Willis and Roberts, 1996) (but see Collete, 1986 for a higher inter-annual variation in adult numbers). This strongly suggests that substantial post-recruitment mortality takes place and may be an important determinant of the structure of the intertidal fish assemblage.

\section{Factors that may control rocky intertidal fish populations}

The evidence presented in the previous section indicates that neither recruitment, nor large disturbances are likely to completely explain the structure of rocky intertidal fish assemblages. Strong inter-annual correlations of numbers of each species that emerge when the same set of pools is sampled in different years, suggests that strongly deterministic mechanisms may act so that each pool seems to support a limited number of fish of each species and size class. Our own experiments support this hypothesis (Faria and Almada, 1999, 2001a). When individuals of a given species were removed from pools, the numbers of fish of that species tended to return to preexperimental levels after two weeks. When, instead of removal, we added fish of a given species to the pool, their numbers also returned to preexperimental levels in similar time intervals. In both removal and addition experiments, the numbers of fish of other species present in the same pools did not change beyond what would be expected by chance, as measured in control pools. Moreover, fish that entered or left the pools after removing or adding individuals were not newly settled juveniles (Faria and Almada, 2001a).
Most studies so far, have not demonstrated interspecific competition for food or shelter (e.g. Gibson, 1972; Koppel, 1988; Mayr and Berger, 1992), or any other effect of species domination, although it must be recognized that most studies evaluated resilience and were not designed to detect competition. Lack of evidence may reflect insufficient rigor in the investigation to address this question. We recommend concentrating future studies on individual species and interactions among groups of two or three species at one time. Mechanisms controlling the numbers of different species in any one pool may differ and need to be identified individually. Such basic knowledge will help to integrate findings across issues and mechanisms. Post-recruitment mortality may be an important factor in the control of rocky intertidal fish populations. Density dependent mortality would explain why variation in the numbers of newly settled recruits is much more pronounced than variation in the number of larger juveniles and adults. Sporadic episodes of high mortality may occur for fishes that are near their distribution limits, when unexpected extreme physical conditions occur, such as cold water intrusion in subtropical fishes reported by Thomson and Lehner (1976). But when we excluded these extreme and rare events, we could not find evidence of mortality caused by unpredictable physical disturbances, as opposed to the situation frequently found in coral reefs (Barlow, 1981). Although we assume that mortality due to harsh conditions is probably rare, we are aware that it is very difficult to detect dead fish after a storm. Thus, it is likely that sudden mortality of this sort has gone underdetected or unreported in the literature.

Information on the role of predation in the rocky intertidal is also limited. The numbers of species and individuals of piscivorous fish are usually low in most rocky intertidal fish assemblages studied. There are at least three sources of predation whose impacts are very difficult to assess: aquatic birds, piscivorous fish that may visit the rocky intertidal during high-tide and invertebrates. We made several incidental observations during our own field-work of sea-anemones that capture small juvenile fish. These juveniles were unfamiliar with the pools or were distracted from their usual behaviour by attempts to capture them. Large numbers of small fish (2-3 cm long) may be consumed by sedentary predatory invertebrates 
without detection. Some rocky intertidal resident fish that are not specialized piscivores, may sometimes consume small conspecific or juveniles of other species. In our study area, G. cobitis, a fish known to eat large amounts of algae, has been observed cannibalizing juvenile conspecifics and other fish both in captivity and in the wild (unpublished data).

Several studies have demonstrated that structural features of rocky intertidal pool habitat may be good predictors of fish abundance (e.g. Bennett and Griffiths, 1984; Mahon and Mahon, 1994; Willis and Roberts, 1996; Griffiths, 2003). Microtopography of rocks, algal cover and shelter availability may affect the numbers of individuals of any given species. We hypothesize that, as a function of size, relief and biotic cover, each pool may provide a limited number of favourable sites for fish of a given species and size, where they can be safe from predators and shelter during low tide or against rough water. If this hypothesis is correct, intraspecific competition for favourable sites may be a major determinant of population size and structure. It would explain why the numbers of a given species in a given pool tend to be remarkably similar between different years, and why fish numbers tend to return to preexperimental levels after additions or removals. This hypothesis would also explain the role of agonistic behaviour found in rocky intertidal fishes of many different families, which is present in juveniles and adults of both sexes without any obvious link to reproduction (e.g. Blennidae, Clinidae, Cotidae, Gobiidae, Gobiesocidae, Physidae, Pomacentridae, Sparidae, Tripterygidae) (for reviews see Gibson, 1969, 1982, 1986; Gibson and Yoshiyama, 1999; additional information can be found in Mayr and Berger, 1992; Almada et al., 1996b; Gonçalves et al., 1996; Faria et al., 1998; Gonçalves and Almada, 1998; Faria and Almada, $2001 \mathrm{~b}$; Estabrook et al., 2002). This kind of behaviour, although very common in many rocky intertidal species, is absent or reduced in some other species (e.g. in some cottids, see Gibson, 1982).

Gibson (1968) suggested that juveniles of $L$. pholis display a kind of diffuse territoriality whereby dominant individuals have priority of access to a given site, although they do not occupy it permanently, and may use several sites. The studies of other rocky intertidal fish suggest the same pattern (e.g. Almada et al., 1983; Mayr and Berger, 1992; Faria et al., 1998; Faria and Almada, 2001b). Although most studies have been done in captivity and may not be fully applicable to natural conditions, it is plausible that this wide spread agonistic behaviour may help dominant individuals to assure their right to occupy the most favourable sites in a given area, even though they do not occupy permanent territories. Each fish would have a network of preferred sites, and familiar pathways where it can safely move. Arondson (1951), Almada et al. (1983) and Gibson (1968) noted that gobies and blennies, when chased in pools, tend to use a limited number of escape itineraries and tend to seek shelter in sites with which they are often familiar. This became obvious when sites where fishes had been observed to hide in on previous occasions were artificially obstructed. In this situation, when chased, fish swam almost directly to a limited number of shelter sites and pushed against the obstructing material, suggesting that they had previous experience with the shelter, made unexpectedly inaccessible (Almada et al., 1983).

The most intense agonistic interactions described for rocky intertidal resident fish tend to involve similar sized individuals (e.g. Gibson, 1968; Wirtz, 1978; Faria et al., 1998; Faria and Almada, 2001b), those that are most likely to compete for the same type of preferred sites for rest and shelter. In line with the hypothesis outlined above, fish that are unable to get favourable positions in a given pool would be more likely to move out and explore other pools. This process could produce the observed patterns, and would be a deterministic mechanism capable of explaining the stability of fish numbers in pools, even without strong interspecific competition. If our view is correct, predation and intraspecific competition for favourable sites will tend to act in concert. Fish that are less able to get ready access to sites best suited for their size would be forced to spend more time in less favourable habitat, being more exposed to predators and also to unfavourable physical conditions (Behrents, 1987).

Fish of very different sizes would compete less for the same sites because their physical requirements are very different. Thus, except in species where large fish cannibalize small juveniles, a pool would contain fish of different sizes, although the numbers of each size would be limited. It is 
interesting to note that similar mechanisms seem to operate in some coral reef fish assemblages. Although in coral reefs insufficient recruitment may lead to variations in juveniles and adults, in others the supply of larvae competent to settle seems not to be a limiting factor, and regulation is density dependent taking place after recruitment. In these cases, competition for shelter and predation are often major factors controlling the number of adults (e.g. Doherty, 2002; Hixon and Webster, 2002; Webster, 2003). In a study of subtidal blenioids, Buchheim and Hixon (1992) found that individuals that are not able to secure proper shelter became highly vulnerable to predation, so that the availability of shelters placed a limit on the density of local populations. This is just the type of mechanism that we suggest may be operating in many of the rocky intertidal resident fish species.

This hypothesis does not imply however that interspecific competition is unimportant as a factor structuring rocky intertidal fish assemblages (for a discussion of interspecific competition see Gibson and Yoshiyama, 1999). Indeed, fishes of different species engage in both intra- and interspecific agonistic encounters and it is possible to assess the relative contributions of differences in size and aggressiveness in determining the outcomes of agonistic encounters. In a laboratory study, Faria et al. (1998) found that mixed groups of $L$. pholis and G. cobitis juveniles and of C. galerita adults of both sexes regularly engage in inter- and intraspecific aggression. Although size was related to dominance in intraspecific interactions, in interspecific encounters between similar sized fish, C. galerita dominated the two other species, while L. pholis dominated G. cobitis. It is likely that in some cases fishes of different species may have similar requirements for shelter, especially when they are in similar class sizes. Properly planned field studies may help to test these hypotheses.

\section{A methodological issue: the problem of destructive sampling}

The majority of studies reviewed used ichtyocides that kill all the fish present in sampled pools. The invertebrate fauna is also often disturbed (Collete, 1986; Mistry et al., 1989). This approach raises both ethical and methodological problems. Ethi- cally, many fish are killed, in our view without any acceptable justification. Indeed, in many cases large numbers of fish have been killed to census the pool $(\mathrm{N}=200$ to 13,700 , see Table 1$)$. Many of these same fish could have been marked, if the aim was only to count them, or transferred to pools sufficiently far apart to prevent their return to the study site, if the aim was to remove the existing icthyofauna. It is almost certain that sedentary rock intertidal fish would not be able to return to their pool if placed for instance some kilometers away from its original location. These distances can be determined experimentally, with the additional benefit of increasing our knowledge of homing behaviour of littoral fishes. These options are feasible, as the use of anaesthetics, if properly employed, can avoid killing the fish (Gibson, 1967b; Griffiths, 2000). We are aware that anaesthetics can have negative effects on fish or their potential consumers, so their choice must be carefully considered. We think however, that the benefits of avoiding killing fish justifies the efforts to develop less noxious anaesthetics. In addition, the live fish may be used in additional experiments in pools located far from their source.

Finally, in many circumstances we can avoid anaesthetizing the fish. Drying out the pools, as employed by Griffiths (2003), is another option for small pools. We have demonstrated statistically that exhaustive collecting by hand-net and probing hole habitats and crevices may yield samples that do not differ statistically from those obtained with anaesthetics (Faria and Almada, 1999). These considerations lead us to conclude that the use of poisons is no longer required as a means to sample tide-pool fishes. We believe that similar arguments are valid to several other types of communities. With increasing attention given to avoiding killing fish, many experiments conducted in habitats so distinct as coral reefs or small streams could possibly be done with a lower level of animal mortality.

Methodological poisoning in pools makes it impossible to selectively remove specific species or size classes, an approach that may help to understand the dynamics of these assemblages. Destructive sampling also prevents the study of the rates at which fishes present in a pool, at any given time, are replaced by new-colonizers or persist in their original pool. Such information could be gained only if the fish collected in each sampling 
occasion were marked as individuals and returned alive and healthy to their pool. Finally, this approach restricts experimental work by depriving the researchers of control pools (in which the fishes are counted and returned to the pool) to compare with disturbance pools (where fishes are added or removed). In long-term surveys, where a large number of nearby pools are involved, experimental depletion of the fauna may take place as noted above, making it difficult to distinguish natural fluctuations from those inadvertently caused by the destructive sampling. Thus, killing fish in assemblage studies is a technique of very limited interest from a methodological perspective.

\section{Future research}

To end this review we would like to address two additional issues that require further investigation. One is the need to conduct ecological and behavioural studies during high tide. It is much easier to collect large amounts of data when the tide is low, but we must keep in mind that most fish are less active during low-tide and many of the most interesting events in the ecology of this assemblage do not occur in these periods. The other is the comparison of the rocky intertidal residents with other components of the rocky intertidal icthyofauna and the subtidal fish assemblages.

The non-resident components of the intertidal fish assemblages include many pelagic and bentho-pelagic fish, which are often juvenile stages of non-intertidal fish (Gibson and Yoshiyama, 1999). The processes involved in the control of their numbers may be quite different from those of resident fish. In coral reefs and in rocky subtidal habitats there are many reports of substantial fluctuations on the composition of fish assemblages, often with important stochastic components (e.g. Sale, 1977, 1978, 1979, 1980; Overholtz and Tyler, 1984; Kruuk et al., 1988; Rossi-Wongtschowski and Paes, 1993; Magill and Sayer, 2002; Pihl and Wennhage, 2002). Both in coral reefs and subtidal rocky habitat, there are species that belong to the same families that dominate rocky intertidal resident assemblages. Subtidal members of these families often share many ecological and life history traits with their counterparts. They tend to be small benthic, often cryptic, fish with lifespans of a few years, and typically provide parental care to demersal eggs (Thresher, 1984). It would be of great interest to know the temporal patterns of variation of these small benthic fish in subtidal habitat (e.g. Stephens et al., 1984; Buchheim and Hixon, 1992). This research will help to clarify to what extent the characteristics summarized in this review are specific to the intertidal habitat or a consequence of the basic morphology, life history and behaviour of small benthic fish.

\section{Acknowledgements}

Part of this study was supported by Fundação para a Ciência e Tecnologia (FCT) as part of the Plurianual Program (UI\&D 331/94) and by FCT and FEDER as part of the Project POCTI/BSE/ 46825/2002. C. Faria was also supported by a grant from FCT (SFRH/BPD/14478/2003). We thank E. Gonçalves and one anonymous Referee for their helpful comments on the manuscript.

\section{References}

Almada, V., Dores, J., Pinheiro, A., Pinheiro, M. and Santos, R.S. (1983) Contribuição para o estudo do comportamento de Coryphoblennius galerita (L.) (Pisces: Blenniidae). Mem. Mus. Mar Ser. Zool. 2(24), 1-165.

Almada, V.C., Carreiro, H., Faria, C. and Gonçalves, E.J. (1996a) The breeding season of Coryphoblennius galerita in Portuguese waters. J. Fish Biol. 48, 295-297.

Almada, V.C., Amorin, C, Almada, F, Matos, R., Pereira, E. and Godinho, R. (1996b) Agonistic behaviour and sound production in Gaidropsarus mediterraneus (Gadiidae). J. Fish Biol. 49, 363-366.

Arondson, I.R. (1951) Orientation and jumping behavior in the gobiid fish Bathygobius soporator. Amer. Mus. Novit. 1480, 122.

Auster, P.J. (1988) A review of the present state of understanding of marine fish communities. J. Northw. Atl. Sci. 8, 67-75.

Barlow, G.W. (1981) Patterns of parental investment, dispersal and size among coral-reef fishes. Environ. Biol. Fish 6, 65-85.

Beckley, L.E. (1985) Tide-pool fishes: recolonization after experimental elimination. J. Exp. Mar. Biol. Ecol. 85, 287-295.

Behrents, K.C. (1987) The influence of shelter availability on recruitment and early juvenile survivorship of Lythrypnus dalli Gilbert (Pisces: Gobiidae). J. Exp. Mar. Biol. Ecol. 107, 45-59.

Bennett, B.A. and Griffiths, C.L. (1984) Factors affecting the distribution, abundance and diversity of rock pool fishes on the Cape Peninsula, South Africa. S. Afr. J. Zool. 18, 343-352.

Brock, R.E., Lewis, C. and Wass, R.C. (1979) Stability and structure of a fish community on a coral patch reef in Hawaii. Mar. Biol. 54, 281-292. 
Buchheim, J.R. and Hixon, M.A. (1992) Competition for shelter holes in the coral-reef fish Achanthemblemaria spinosa Metzlaar. J. Exp. Mar. Biol. Ecol. 164, 45-54.

Collette, B.B. (1986) Resilience of the fish assemblage in New England tidepools. Fish. Bull. 84(1), 200-204.

Connell, J.H. (1972) Community interactions on marine rocky intertidal shores. Аnпи. Rev. Ecol. Syst. 3, 169-192.

Davies, J.L.D. (2000) Changes in a tidepool fish assemblage on two scales of environmental variation: seasonal and El Niño Southern Oscillation. Limn. Oceanog. 45(6), 1368-1379.

Dayton, P.K. (1971) Competition, disturbance, and community organization: the provision and subsequent utilization of space in a rocky intertidal community. Ecol. Monogr. 41, 351-389.

Dayton, P.K. (1973) Dispersion, dispersal and persistence of the annual intertidal alga, Postelsia palmaeformis Ruprecht. Ecology 54, 433-438.

Dayton, P.K. (1975) Experimental evaluation of ecological dominance in a rocky intertidal algal community. Ecol. Monogr. 45, 137-159.

Doherty, P.J. (1983) Tropical territorial damselfishes: is density limited by aggression or recruitment? Ecology 64(1), 176190.

Doherty, P.J. (2002) Variable replenishment and the dynamics of reef fish populations. In: Sale, P.F. (ed.), Coral Reef Fishes. Dynamics and diversity in a complex ecosystem, San Diego, CA, pp. 327-355.

Dufour, V. and Galzin, R. (1992) Le recrutement des poisons recifaux sur l'ile de Moorea, Polynésie Française. Impact sur la dynamique des populations et consequences sur la gestion des stocks. Cybium 16(4), 267-277.

Estabrook, G.F., Almada, V.C., Almada, F.J. and Robalo, J.I. (2002) Analysis of conditional contingency using ACTUS2 with examples from studies of animal behavior. Acta Ethol. 4, 73-80.

Faria, C. and Almada, V. (1999) Variation and resilience of rocky intertidal fish in western Portugal. Mar. Ecol. Prog. Ser. 184, 197-203.

Faria, C. and Almada, V. (2001a) Microhabitat segregation in three rocky intertidal fish species in Portugal: does it reflect interspecific competition? J. Fish Biol. 58, 145-159.

Faria, C. and Almada, V. (2001b) Agonistic behaviour and control of access to hiding places in two intertidal blennies, Lipophrys pholis and Coryphoblennius galerita (Pisces: Blenniidae). Acta Ethol. 4, 51-58.

Faria, C., Almada, V.C. and Gonçalves, E.J. (1996) Juvenile recruitment, growth and maturation of Lipophrys pholis (Pisces: Blenniidae), from the west coast of Portugal. J. Fish Biol. 49, 727-730.

Faria, C., Almada, V. and Nunes, M.C. (1998) Patterns of agonistic behaviour, shelter occupation and habitat preference in juvenile Lipophrys pholis, Coryphoblennius galerita and Gobius cobitis. J. Fish Biol. 53, 1263-1273.

Fogarty, M.J., Sissenwine, M.P. and Cohen, E.B. (1991) Recruitment variability and the dynamics of exploited marine populations. Trends Ecol. Evol. 6, 241-246.

Gibson, R.N. (1967a) Studies on the movements of littoral fish. J. Anim. Ecol. 36, 215-234.

Gibson, R.N. (1967b) The use of the anaesthetic quinaldine in fish ecology. J. Anim. Ecol. 36, 295-301.

Gibson, R.N. (1968) The agonistic behaviour of juvenile Blennius pholis L. (Teleostei). Behaviour 30, 192-217.
Gibson, R.N. (1969) The biology and behaviour of littoral fish. Oceanogr. Mar. Biol. Ann. Rev. 7, 367-410.

Gibson, R.N. (1972) The vertical distribution and feeding relationships of intertidal fish on the atlantic coast of France. J. Anim. Ecol. 41(1), 189-207.

Gibson, R.N. (1982) Recent studies on the biology of intertidal fishes. Oceanogr. Mar. Biol. Ann. Rev. 20, 363-414.

Gibson, R.N. (1986) Intertidal teleosts: life in a fluctuating environment. In: Pitcher, T.J. (ed.) The Behaviour of Teleost Fishes, London, pp. 388-408.

Gibson, R.N. and Yoshiyama, R.M. (1999) Intertidal fish communities. In: Horn, M.H., Martin, K.L.M. and Chotkowski, M.A. (eds.), Intertidal Fishes. Life in two worlds, San Diego, CA, pp. 264-296.

Godínez-Domínguez, E., Rojo-Vázquez, J., Galván-Piña, V. and Aguilar-Palomino, B. (2000) Changes in the structure of a coastal fish assemblage exploited by a small scale gillnet fishery during El Niño-La Niña event. Estuar Coast. Shelf Sci. 51, 773-787.

Gonçalves, E.J. and Almada, V.C. (1998) A comparative study of territoriality in intertidal and subtidal blennioids (Teleostei, Blennioidei). Environ. Biol. Fish 51, 257-264.

Gonçalves, E.J., Almada, V.C., Almeida, S.P., Gonçalves, D.M., Repas, M. and Simões, N. (1996) Observations on the agonistic behaviour of Lepadogaster lepadogaster purpurea (Pisces: Gobiesocidae). J. Fish Biol. 49, 367-369.

Griffiths, S.P. (2000) The use of clove oil as an anaesthetic and method for sampling intertidal rockpool fishes. J. Fish Biol. 57, 1453-1464.

Griffiths, S.P. (2003) Spatial and temporal dynamics of temperate Australian rockpool ichthyofaunas. Mar. Fresh. Res. 54(2), 163-176.

Grossman, G.D. (1982) Dynamics and organization of a rocky intertidal fish assemblage: the persistence and resilience of taxocene structure. Am. Nat. 119(5), 611-637.

Grossman, G.D. (1986) Long term persistence in a rocky intertidal fish assemblage. Environ. Biol. Fish 15(4), 315317.

Harger, J.R.E. and Landenberger, D.E. (1971) The effect of storms as a density-dependent mortality factor on populations of sea mussels. Veliger 14, 195-201.

Hixon, M.A. and Webster, M.S. (2002) Density dependence in reef fish populations. In: Sale, P.F. (ed.) Coral Reef Fishes. Dynamics and Diversity in a Complex Ecosystem, San Diego, CA, pp. 303-325.

Houde, R.D. (1987) Fish early life dynamics and recruitment variability. Am. Fish. Soc. 2, 17-29.

Itzkowitz, M. (1977) Spatial organization of the Jamaican damselfish community. J. Exp. Mar. Biol. Ecol. 28, 217241.

Jones, G.P. (1987a) Competitive interactions among adults and juveniles in a coral reef fish. Ecology 68(5), 1534-1547.

Jones, G.P. (1987b) Some interactions between residents and recruits in two coral reef fishes. J. Exp. Mar. Biol. Ecol. 114, 169-182.

Koppel, V.H. (1988) Habitat selection and space partitioning among two Mediterranean blenniid species. Mar. Ecol. 9(4), 329-346.

Kruuk, H., Nolet, B. and French, D. (1988) Fluctuations in numbers and activity of inshore demersal fishes in Shetland. J. Mar. Biol. Ass. UK 68, 601-617. 
Larson, R.J. (1980a) Competition, habitat selection and the bathymetric segregation of two rockfish (Sebastes) species. Ecol. Mongr. 50, 221-239.

Larson, R.J. (1980b) Territorial behaviour of the black and yellow rockfish and gopher rockfish (Scorpaenidae, Sebastes). Mar. Biol. 58, 111-122.

Larson, R.J. (1980c) Influence of territoriality on adult density in two rockfishes of the genus Sebastes. Mar. Biol. 58, 123-132.

Letourner, Y. (1996) Dynamics of fish communities on Reunion fringing reefs, Indian Ocean. II. Patterns of temporal fluctuations. J. Exp. Mar. Biol. Ecol. 195, 31-52.

Magill, S.H. and Sayer, M.D.J. (2002) Seasonal and interannual variation in fish assemblages of northern temperate rocky subtidal habitats. J. Fish Biol. 61, 1198-1216.

Mahon, R. and Mahon, S.D. (1994) Structure and resilience of a tidepool fish assemblage at Barbados. Environ. Biol. Fish 41, 171-190.

Mayr, M. and Berger, A. (1992) Territoriality and microhabitat selection in two intertidal New Zealand fish. J. Fish Biol. 40, 243-256.

Mistry, S.D., Lizerbrom, E.K. and Parton, E.R. (1989) Shortterm ichthyofaunal recruitment in northern California tidepools. Copeia 1989(4), 1081-1084.

Overholtz, W.J. and Tyler, A.V. (1984) Long-term responses of the demersal fish assemblages of Georges Bank. Fish. Bull. 83(4), 507-520.

Pihl, L. and Wennhage, H. (2002) Structure and diversity of fish assemblages on rocky and soft bottom shores on the Swedish west coast. J. Fish Biol. 61(suppl. A), 148-166.

Polivka, K.M. and Chotkowski, A. (1998) Recolonisation of experimentally defaunated tidepool by northeast Pacific intertidal fishes. Copeia 1998(2), 456-462.

Rogers, S.I. and Millner, R.S. (1996) Factors affecting the annual abundance and regional distribution of English inshore fish populations: 1973 to 1995. J. Mar. Sci. 53, 1094-1112.

Rossi-Wongtschowski, C.L.D.B. and Paes, E.T. (1993) Padrões espaciais e temporais da comunidade de peixes demersais do litoral norte do Estado de São Paulo - Utatuba, Brasil. Pub. Esp. Inst. Oceanogr., S Paulo 10, 169-188.

Sale, P.F. (1975) Patterns of use of space in a guild of territorial reef fishes. Mar. Biol. 29, 89-97.

Sale, P.F. (1977) Maintenance of high diversity in coral reef fish communities. Am. Nat. 111, 337-359.

Sale, P.F. (1978) Coexistence of coral reef fishes - a lottery for living space. Environ. Biol. Fish 3(1), 85-102.

Sale, P.F. (1979) Recruitment, loss and coexistence in a guild of territorial coral reef fishes. Oecologia 42, 159-177.

Sale, P.F. (1980) Assemblages of fish on patch reefs predictable or unpredictable? Environ. Biol. Fish 5, 243-249.

Silberschneider, V. and Booth, D.J. (2001) Resource use by Enneapterygius rufopileus and other rockpool fishes. Environ. Biol. Fish 61, 195-204.

Sousa, W.P. (1979) Disturbance in marine intertidal boulder fields: the non-equilibrium maintenance of species diversity. Ecology 60, 1225-1239.

Stephens, J.S., Morris, P.A., Zerba, K. and Love, M. (1984) Factors affecting fish diversity on a temperate reef: the fish assemblage of Palos Verdes Point, 1974-1981. Environ. Biol. Fish II(4), 259-275.

Thomson, D.A. and Lehner, C.E. (1976) Resilience of a rocky intertidal fish community in a physically unstable environment. J. Exp. Mar. Biol. Ecol. 22, 1-29.

Thresher, R.E. (1984) Reproduction in Reef Fishes. T.H.F. Publications, Neptune City, NJ, 399 pp.

Webster, M.S. (2003) Temporal density dependence and population regulation in a marine fish. Ecology 84(3), 623-628.

Willis, T.J. and Roberts, C.D. (1996) Recolonisation and recruitment of fishes to intertidal rockpools at Wellington, New Zealand. Environ. Biol. Fish 47, 329-343.

Wirtz, P. (1978) The behaviour of the Mediterranean Tripterygion species (Pisces, Blennioidei). Z. Tierpsychol. 48, 142-174. Yoshiyama, R.M., Sassaman, C. and Lea, R.N. (1986) Rocky intertidal fish communities of California: temporal and spatial variation. Environ. Biol. Fish 17(1), 23-40. 